\title{
Missed Isolated Transverse Colon Injury following Trauma at a Tertiary Hospital in Nigeria
}

\author{
OJ Ogundele ${ }^{1}$ and KI Egbuchulem ${ }^{2 *}$ \\ ${ }^{1}$ Department of Orthopedics and Trauma, University College Hospital, Ibadan, Nigeria \\ ${ }^{2}$ Department of Surgery, University College Hospital, Ibadan, Nigeria
}

*Corresponding author: Dr Ifeanyichukwu Kelvin Egbuchulem, Department of Surgery, University College Hospital, PMB 5116,

Ibadan 200212, Nigeria

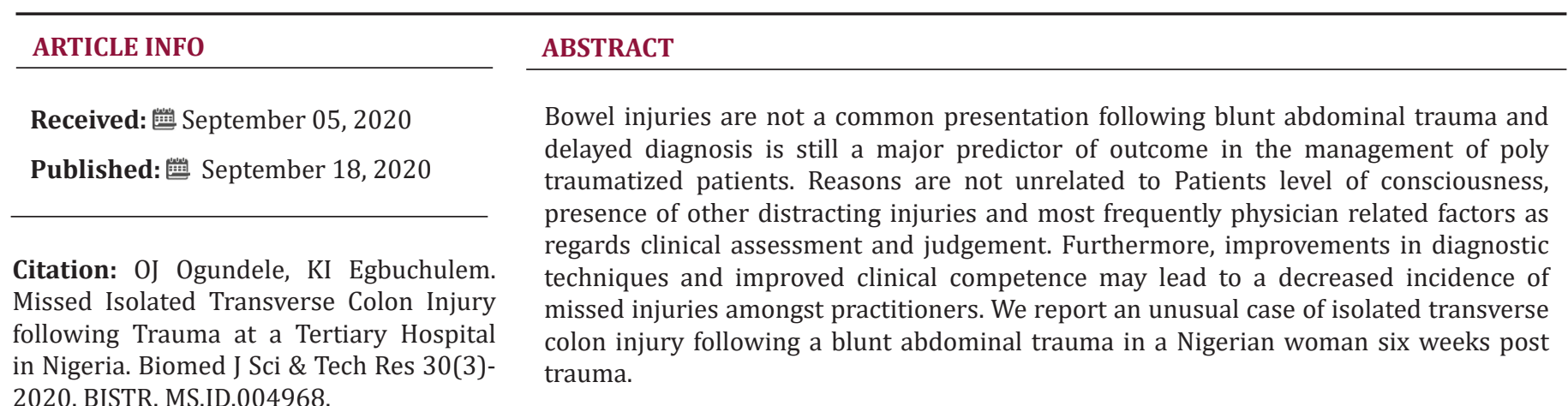

Keywords: Missed; Transverse Colon Injury; Trauma; Nigeria

\section{Introduction}

Missed injuries have been defined by several authors some have used how clinically significant the missed injuries are [1,2] while others have used the length of time from injury to diagnosis $[1,3]$. Missed injuries therefore are injuries associated with high morbidity and mortality as a result of a delayed diagnosis [1,2] or the requirement of further surgical procedures as criteria to define clinically significant missed injuries [4]. Penetrating abdominal injuries are the commonest cause of colonic injury, however it is a rare presentation in blunt abdominal trauma [5]. Hollow viscous injuries such as the bowels account for $17.8 \%$ of all missed injuries in blunt abdominal trauma in comparison to solid organs such as the spleen (8.9\%) and liver (3.3\%); as such, a hollow viscous injury is the most frequently missed organ injury [6]. The accurate diagnosis of blunt gastrointestinal tract injuries is therefore very pertinent. Early diagnosis is a sine qua non in achieving a favorable outcome. We report an unusual case of isolated transverse colon injury that was missed six weeks post trauma in a Nigerian woman and reviewed relevant literatures.

\section{Case Presentation}

A.0 was a 20-year-old Nigerian female student who was admitted with a one hour history of inability to bear weight on the lower limbs following a Pedestrian-Motor vehicular accident. There were associated transient loss of consciousness and injury to the lower limbs. However, there was no history of seizure or bleeding from cranio-facial orifices. Initial care was at a peripheral hospital before she was referred to our facility. There is no history of intercurrent medical illness. She does not smoke cigarette nor take alcohol. She is the first of six children in a monogamous family. At presentation she was conscious oriented in time, place, and person; not pale, mildly dehydrated. Chest and cardiovascular examination were essentially normal. Abdominal examination showed a positive pelvic compression test. Digital rectal examination showed normal findings. Musculoskeletal examination did not reveal any spinal abnormality; however, patient could not straight leg raise bilaterally.

A diagnosis of Pelvic fracture secondary to Pedestrian-Motor vehicular accident was made. She was admitted and placed on bed rest. She was also commenced on analgesics, Tabs tramadol, diclofenac, and anticoagulant with warfarin. X-ray of the pelvis done at presentation showed fracture of the left superior and inferior pelvic rami, widening of the symphysis, widening of the sacroiliac joints bilaterally with no vertical shear component. A radiolucent area on the inferior pubic rami was also noted. Cervical-spine x-ray 
showed straightening of the $\mathrm{C}$-spine angulation at the junction of the 5th and 6th cervical vertebrae. X-ray of the lower limbs and chest were essentially normal. At about six weeks on bed rest she developed colicky abdominal pain, more in the epigastrium and sometimes radiating to the back. There was associated non-bilious vomiting containing recently ingested food. Two days following the onset of abdominal pain she developed progressive abdominal distension with abdominal pain becoming generalized. There was no associated constipation. Further examination revealed an acutely ill looking young female, febrile (380C) with a distended abdomen that moves slowly with respiration. There is generalized tenderness, guarding and rebound tenderness and bowel sounds were hypoactive.

Digital rectal examination revealed poor peri-anal hygiene, good anal sphincteric tone, no palpable rectal mass, rectum contain scanty well-formed feces and gloved finger was stained with black feces. A diagnosis of acute abdomen secondary to ruptured appendix; perforated peptic ulcer disease were considered. She was nursed in fowler's position; nasogastric tube passed drained $250 \mathrm{mls}$ of effluent over an 8 hour period. A 4 hourly abdominal girth measurement was also commenced. An abdominopelvic ultrasound scan showed free intra peritoneal fluid within the Morrison's pouch, right paracolic gutter and the pelvis with bowel loops seen floating within the fluid. The visualized bowel loops are normal in caliber but shows reduced peristalsis. The liver, span was $15.4 \mathrm{~cm}$ with normal echo texture and outline. The spleen was $12.1 \mathrm{~cm}$, normal size and echo texture. Kidneys, uterus, urinary bladder and adnexa were normal in echogenicity. Plain abdominal X-ray done showed multiple air fluid levels. A diagnosis of generalized peritonitis secondary to perforated peptic ulcer disease was made thereafter. She was resuscitated and worked up for exploratory laparotomy.

Intra operative findings were extensive intra peritoneal adhesions, a $4 \times 3 \mathrm{~cm}$ perforation with ragged edges at the mid posterior portion of the transverse colon and $1.5 \mathrm{~L}$ purulent intra peritoneal fluid. She had a transverse loop colostomy from the perforated transverse colon and peritoneal lavage. In the immediate post-operative period she developed tachypnea ( $>40$ / $\mathrm{min}$ ) and tachycardia (>120/min). She was managed for about 48 hours in the intensive care unit wherein she had thoracentesis done in the left hemi thorax which yielded $150 \mathrm{mls}$ of sero-sanguineous fluid. She commenced oral intake soon after the colostomy became functional. Check X-ray of the pelvis done at 8th week on bed rest showed scanty callous formed around the fracture site. She made good clinical improvement and was discharged home subsequently.

\section{Discussion}

Trauma is emerging as a leading cause of death and significant morbidity world over, with developing country like ours not excluded. This has been attributed to increase technological activity especially with the development of high speed automobiles; in addition to this, the poor states of our roads often contribute to this menace [7]. A meta-analysis by Roman et al revealed the median percentage of patients involved in motor vehicle accident accounting for missed injuries as 68\% (range, 46-84.6\%) and $92 \%$ (range, $88-100 \%$ ) of them sustained a blunt trauma [8]. The incidence of missed injuries and delayed diagnoses reported in the literature is $1.3 \%$ to $39 \%[1-3,9,10]$ This incidence is worrisome as approximately $27-66 \%$ of all delayed diagnoses or missed injuries were major injuries with high morbidity and mortality [8]. Adesanya et al in Lagos found from his study on pattern of civilian abdominal gunshot injuries that the commonly injured organs in decreasing order were the small bowel (56.1\%), colon (38.6\%), liver $(22.8 \%)$ and stomach (19.3\%) [11]. However, in blunt abdominal injury solid organ such as the spleen (74\%) is the commonest injured organ [12]. The scenario in our patient was an isolated transverse colon injury following a blunt trauma which is skewed away from the usual presentation.

Patients who have been severely injured in road accidents, especially those with head injury, and a greater Injury Severity Score, are more likely to have missed injuries [1,3,9]. However, a high index of suspicion should be made when assessing trauma patients irrespective of the severity to avoid missed injury as was observed in our patient. Some investigators report missed injuries in multiple trauma patients; 2 other authors describe unrecognized injuries in patients with abdominal [13] and orthopedic trauma [14]. Our patient presented with a mild head injury and pelvic injury with no clinical feature of abdominal injury at presentation, but this gradually evolved to generalized peritonitis six weeks post trauma. A possible relationship between delay of diagnoses and morbidity was reported in a study by Vles [3]. Some studies have reported high rates of mortality 1, 10, and 13 among trauma patients with missed injuries. The anatomical location of the injury has correlation with morbidity and mortality. For hollow viscous injuries following blunt abdominal trauma, gastric injuries have a higher mortality rate compared to $15.2 \%$ for small bowel injuries and $19.4 \%$ for colon and rectal injuries. [15] A study done at Aminu Kano Teaching Hospital involved 58 patients of whom Forty nine had clear failures of care from consensus of the reviewing panel of surgeons. Out of the 19 non central nervous system mortalities three had missed injuries (6.1\%) [16].

Similarly, Ameh et al did a retrospective study of children aged 12 years or less managed for ano rectal injury over a 10 year period. Out of the seven children studied, an intra rectal injury was missed at initial assessment in one female who eventually died of peritonitis from a missed intra rectal injury [17]. At present, the management of blunt abdominal trauma especially in children was preferably non-operative but with increased likelihood of missed gastrointestinal tract injury [18]. Since obvious features may not be present at initial examination and the result of investigations often non-specific, the diagnosis of gastrointestinal tract injury requires 
repeated examination and a high index of suspicion. Intra-operative manoeuvre is dependent on findings at surgery, which correlates with the Eastern Association for the Surgery of Trauma practice management guidelines. Some clinicians have employed peritoneal lavage and primary repair of perforation after refreshing the margins [19]. However, in our patient, a transverse loop colostomy from the perforated transverse colon and peritoneal lavage was offered because of the findings at surgery of Grade III American Association for the Surgery of Trauma (AAST) colonic injury.

Some studies have demonstrated that trauma patients with missed injuries requires significantly longer hospital stays (15.7 - 42.1 days versus 7.9 - 26.7 days) and longer intensive care unit stays (5.4 - 10.9 days versus 1.5 - 5.7 days), than those without missed injuries $[2,10]$. Our index patient stayed fifty six days on admission and seventy two hours in intensive care unit before discharge. Several factors have been implicated as causes of missed injury; such as clinical inexperience (26.5\%) 20 and assessment errors (33.8-60.5\%) [2,9] and 10 Other investigations found additional contributing factors such as technical errors [9]. Janjua and Kremli et al in their studies noted that patients with missed injuries tend to have a combination of contributing factors [20,21]. Janjua et al also found that in $50 \%$ of cases, more than one factor was responsible for the occurrence of missed injury. To reduce the rate of missed injuries, we must focus wholly on patient when evaluating them whether as a major or minor case. Furthermore, some authors emphasized the role of tertiary trauma survey in patients with multiple injuries, as significant injuries may be missed during the primary and secondary surveys [3,9] and 10 Over fifty percent of overall missed injuries and ninety percent of clinically significant missed injuries were diagnosed by tertiary trauma survey within 24 hours of admission [3,9]. The onus, therefore, lies on us clinicians to be diligent, seek for knowledge when necessary and imploy a patient centered practice which will help in curbing this medical dilemma.

\section{Conclusion}

Isolated traumatic transverse colon injury complicating missed blunt abdominal injury is an unusual presentation in clinical practice. Timely identification and in-depth clinical evaluation are key to early diagnosis and hence obviate the associated morbidity and mortality. Missed injuries still occur at an unacceptably high rate in trauma patients. The onus, therefore, lies on us clinicians to be diligent when evaluating them especially the tertiary survey, seek for knowledge when necessary and imploy a patient centered practice which will help in curbing this medical enigma and improve patient outcome.

\section{References}

1. Houshian S, Larsern MS, Holm C (2002) Missed Injuries in a Level I Trauma Centre. J Trauma 52(4): 715-719.
2. Buduhan G, Mc Ritchie DI (2000) Missed Injuries in Patients with Multiple Trauma. J Trauma 49(4): 600-605.

3. Vles WJ, Veen EJ, Roukema JA, Meeuwis JD, Leenen LPH (2003) Consequences of Delayed Diagnoses in Trauma Patients: A Prospective Study. J Am Coll Surg 197(4): 596-602.

4. Brooks A, Holroyd B, Riley B (2004) Missed Injury in Major Trauma Patients. Injury 35(4): 407-410.

5. Yi Xiong Zheng, Li Chen, Si Feng Tao, Ping Song (2007) Diagnosis and management of colonic injuries following blunt trauma. World J Gastroenterol 13(4): 633-636.

6. Lawson CM (2011) Missed injuries in the era of the trauma scan. J Trauma 70(2): 452-456.

7. Chandran A, Hyder AA, Peek Asa C (2010) The global burden of unintentional injuries and an agenda for progress. Epidemiologic Reviews 32(1): 110-120.

8. Roman P, Hans Christoph P (2008) Missed injuries in trauma patients: A literature review. Patient Safety in Surgery 2(20): 1-6.

9. Janjua KJ, Sugrue M, Deane SA (1998) Prospective Evaluation of Early Missed Injuries and the role of Tertiary Trauma Survey. J Trauma 44(6): 1000-1007.

10. Kalemoglu M, Demirbas S, Akin ML, Yildirim I, Kurt Y, et al. (2006) Missed Injuries in Military Patients with Major Trauma: Original Study. Military Medicine 171: 598-602.

11. Adesanya AA, Afolabi IR, DA Rocha Afodu JT (1998) Civilian abdominal gunshot wounds in Lagos. R Coll Surg Edinb 43(4): 230-234.

12. Maurice A, Victor N, Mark U, Gabriel U (2012) Blunt Abdominal Trauma in a Teaching Hospital, Calabar, Nigeria. International Journal of Clinical Medicine 3(7): 693-696.

13. Sung CK, Kim KH (1996) Missed Injuries in Abdominal Trauma. J Trauma 41(2): 276-278.

14. Juhl M, Moller Madsen B, Jensen J (1990) Missed Injuries in an Orthopaedic Department. Injury 21(2): 110-112.

15. Watts DD, Fakhry SM (2003) East Multi-institutional Hollow Viscous Injury Research Group. Incidence of hollow viscous injury in blunt trauma: An analysis from 275,557 trauma admissions from the East Multi-Institutional Trial. J Trauma 54(3): 289-294.

16. Usman AG, Abdurrahman AS, Kabir MA, Mohammed Kabir Abubakar (2014) Quality assessment of trauma care in a teaching hospital in North Western Nigeria. Nigerian Journal of Basic and Clinical Sciences. 11(2): 76-79.

17. Ameh EA (2000) Anorectal injuries in children. Paediatr Surg Int 16(56): 388-391.

18. Ulman I, Avanoglu A, Ozcan C, Demircan M, Ozok G (1996) Gastrointestinal perforation in children. A continuing challenge to nonoperative treatment of blunt abdominal trauma. J Trauma 41(1): 110113.

19. Thakur P (2015) A rare case of isolated transverse colon perforation following blunt trauma abdomen-Case report with review of literature. Int Surg J 2(3): 411-413.

20. Chan RNW, Ainscow D, Sikorski JM (1980) Diagnostic Failures in the Multiple Injured. J Trauma 20(8): 684-687.

21. Kremli MK (1996) Missed Musculoskeletal Injuries in a University Hospital in Riyadh: Types of Missed Injuries and Responsible Factors. Injury 27(7): 503-506. 
ISSN: 2574-1241

DOI: $10.26717 /$ BJSTR.2020.30.004968

Dr Ifeanyichukwu Kelvin Egbuchulem. Biomed J Sci \& Tech Res

(c) (i) This work is licensed under Creative

Submission Link: https://biomedres.us/submit-manuscript.php

$\begin{array}{ll}\text { BIOMEDICAL } & \text { Assets of Publishing with us } \\ \text { RESEARCHES } & \text { - Global archiving of articles } \\ \text { - Immediate, unrestricted online access } & \text { - Rigorous Peer Review Process } \\ & \text { - Authors Retain Copyrights } \\ & \text { https://biomedres.us/ }\end{array}$

